\title{
Fast Up-regulation of The LINE-1 ORF2 Proteins in Pulmonary Cells after Exposure to Cigarette Smoke
}

Miglino N, Tamm $\mathbf{M}$ and Borger $\mathbf{P}^{*}$

Department of Biomedicine, University of Basel, Basel, Switzerland

Keywords: Human genome; Cigarette Smoke; LINE-1; Lung fibroblast cell cultures

\section{Short Communication}

Transposable elements (TEs) make up approximately $45 \%$ of the human genome [1]. The biology of the TEs has experienced a remarkable development over the last decade. From being regarded as evolutionary relicts, often called junk DNA, it has become evident that TEs play an important role in shaping and regulating of the human genome. Although TEs exert important physiological functions in the body, they may also contribute to the development of complex diseases, such as autoimmune and neurological diseases, as well as initiate several malignancies and cancers [2]. LINE-1 is among the best characterized TEs in humans. Importantly, LINE-1 is the only TE capable of expressing the entire machinery required for complete transposition and other active TEs move within the genome by L1mediated transposition [3]. Therefore LINE-1 plays a central role in genome dynamics in both germline and somatic cells [4].

In the lung, LINE-1 activity has been associated with increased natural mutagenesis. Somatic L1 insertions occur at high frequencies in lung tumor genomes and may provide novel oncogenic mechanisms [5]. Interestingly, LINE-1 repression may be lost in response to stressinduced DNA damage [6]. The increased LINE-1 activity is associated with a significant reduction in methylation status, indicating epigenetic mechanisms of gene and or genome regulation [7]. Furthermore, LINE-1 activity may damage the DNA via random insertions and endonuclease-dependent DNA double strand breaks [8]. The LINE-1 ORF2 contains both a RT and an endonuclease together with a carboxyterminal DNA binding domain [9].

Tobacco smoke exposure is also the leading cause of COPD and the main risk factor for the development of lung cancers. In the lung, tobacco smoke induces high degree of oxidative stress, which in turn may induce DNA damage and enhance TE activity. With this in mind we assessed LINE-1 activity in primary human pulmonary cells (fibroblasts and airway smooth muscle cells) before and after exposure to cigarette smoke.

Lung fibroblast cell cultures were established from small sections of lung parenchymal tissue and grown in RPMI 1640 (Lonza, Basel) supplemented with $5 \%$ fetal calf serum (FCS), $8 \mathrm{mM}$ l-glutamine, 20 $\mathrm{mM}$ hydroxyethyl piperazine ethane sulfonic acid and $1 \%$ modified Eagle's medium vitamin mix (Gibco, Paisley, UK). Cigarette smokeconditioned medium (SCM) was prepared by passing cigarette smoke of one cigarette of a commercially available brand (Gauloises Blondes; Altadis, Madrid, Spain) with a $60 \mathrm{~mL}$ syringe through $25 \mathrm{~mL}$ RPMI medium in a Schott ${ }^{\circledR}$ flask containing an influx and aspiration channel [10]. Prior to addition of SCM, the cells were serum starved for $24 \mathrm{~h}$ and diluted SCM (10\%) was added in absence of FCS. LINE1 activity was detected with LINE-1 ORF2-specific antibodies (Santa Cruz Biotechnology, H-110, sc-67197) and protein expression was normalised to a-tubulin (Santa Cruz Biotechnology).

As demonstrated in Figure 1, resting primary human airway smooth muscle cells did not express detectable levels of L1-ORF2.

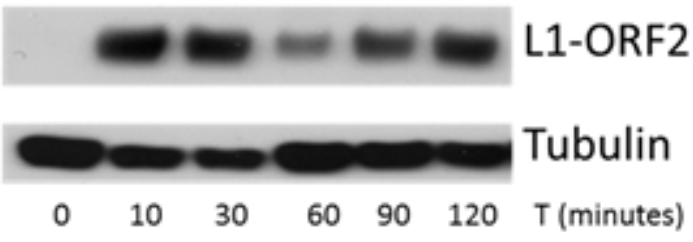

Figure 1: LINE-1 protein (L1-ORF2) expression in primary human airway smooth muscle (ASM) cells cultured in absence and presence of smokeconditioned medium (SCM). Cells were cultured in RMPI without SCM (resting cells; $t=0$ minutes) or in the presence of SCM for $10,30,60,90$ and 120 minutes (as indicated). The applied SCM was used as a $10 \%$ dilution from a stock solution containing the smoke equivalent of 1 cigarette $/ 25 \mathrm{ml}$. The Western blot shown is representative for 5 independently performed experiments.

In the presence of SCM (10\%), we observed a biphasic LINE1-ORF2 expression pattern: an immediate early maximum at 10-30 minutes and a second maximum after 120 minutes. We observed the same pattern of L1-ORF2 protein expression in primary human bronchial fibroblast cell lines that we established from the same pulmonary tissue. Previously we demonstrated that exposure to 10\% SCM induced a complete inhibition of pulmonary fibroblast proliferation [10]. This was associated with a significantly upregulated full-length $\mathrm{C} / \mathrm{EBP} \alpha$ and $\mathrm{C} / \mathrm{EBP} \beta$ proteins due to a shift in the translational control of CEBPA and CEBPB mRNAs involving regulatory mechanisms independent of DNA transcription. Our current data demonstrate that an increased activity of L1-ORF2 is preceding the SCM-induced block of fibroblast proliferation. Currently, it is unclear why this is associated with an immediate increased activity of LINE-1, but we speculate that it may function as an intracellular warning system to immediately terminate all pro-proliferative signals and enter a quiescent state in order to prevent proliferation- and/ or oxidation-associated DNA damage, including the reactivation of integrated viruses. The immediate abrogation of proliferation may thus provide an innate protection mechanism triggered in response to environmental toxins. Cigarette smoke contains ROS at high concentrations and is therefore a potent genotoxic agent [11].

Further, LINE-1 RNA expression levels detected by TaqMan PCR in 3 cell lines did not show significant differences before and after smoke exposure (data not shown), indicating that the L1-ORF protein expression is controlled at the level of translation. Recent studies demonstrated that TE RNA is constitutively and massively expressed in human cells [12], which enables fast biological responses as observed in immediate upregulation of the L1-ORF2 proteins. The LINE-1

${ }^{*}$ Corresponding author: Peter Borger, Department of Biomedicine, University of Basel, Basel, Switzerland, Tel: +49 7639076371; E-mail: pieter.borger@usz.ch

Received April 11, 2018; Accepted April 16, 2018; Published April 21, 2018

Citation: Miglino N, Tamm M, Borger (2018) Fast Up-regulation of The LINE-1 ORF2 Proteins in Pulmonary Cells after Exposure to Cigarette Smoke. J Pulm Respir Med 8: 454. doi: 10.4172/2161-105X.1000454

Copyright: @ 2018 Miglino N, et al. This is an open-access article distributed under the terms of the Creative Commons Attribution License, which permits unrestricted use, distribution, and reproduction in any medium, provided the original author and source are credited. 
RNA itself is ubiquitously present and thus immediately available for translation into proteins or to evoke a non-coding RNA response to halt proliferation.

It should be noted that LINE-1 protein expression itself does not automatically imply de novo LINE-1 insertions into the genomealthough our data do not exclude this possibility. The detection of de novo insertions of LINE-1 sequences should rather be determined using direct assessment techniques [12-14]. The high expression levels of the LINE-1 ORF2 proteins after exposure to SCM signifies the presence of two fundamental proteins of the transposition machinery: L1-encoded reverse transcriptase and endonuclease. Therefore, an increased activity of LINE-1 elements may also indirectly affect the mobility of other mobile elements, such as short interspersed nuclear elements (SINEs), which rely on the LINE-1-encoded protein machinery for transposition. Although LINE-1 mobilization was able to induce DNA double strand breaks [8], indicating that the endonuclease activity of expressed ORF2 is capable of genome destabilization independent de novo insertions, further investigations is required to reveal whether smoking induces DNA damage indirectly through mobilization of SINEs and Aluelements. Taken together, we show that LINE-1 can be reactivated in pulmonary cells, a phenomenon that should be considered when thinking about smoking-induced lung cell proliferation-disorders and developing strategies to prevent and/or treat them.

\section{Funding}

Supported by the Swiss National Science Foundation (Grant: 310030_133109).

\section{References}

1. Levy S, Sutton G, Ng PC, Feuk L, Halpern AL, et al. (2007) The diploid genome sequence of an individual human. PLoS Biol 5: e254.

2. Miglino N, Roth M, Baty F, Brutsche M, Tamm M, et al. (2012) Asthma and the regulated retrotransposon transcriptome. Eur Respir J 40: 788-790.
3. Dewannieux M, Esnault C, Heidmann T (2003) LINE-mediated retrotransposition of marked Alu sequences. Nat Genet 35: 41-48

4. Babatz TD, Burns KH (2013) Functional impact of the human mobilome. Curr Opin Genet Dev 23: 264-270.

5. Iskow RC, McCabe MT, Mills RE, Torene S, Pittard WS, et al. (2010) Natural mutagenesis of human genomes by endogenous retrotransposons. Cell 141: 1253-1261.

6. Van Meter M, Kashyap M, Rezazadeh S, Geneva AJ, Morello TD, et al (2014) SIRT6 represses LINE1 retrotransposons by ribosylating KAP1 but this repression fails with stress and age. Nat Commun 5: 5011.

7. Saito K, Kawakami K, Matsumoto I, Oda M, Watanabe G, et al. (2010) Long interspersed nuclear element 1 hypomethylation is a marker of poor prognosis in stage ia non-small cell lung cancer. Clin Cancer Res 16: 2418-2426.

8. Gasior SL, Wakeman TP, Xu B, Deininger PL (2006) The human LINE-1 retrotransposon creates DNA double-strand breaks. J Mol Biol 357: 1383-1393.

9. Piskareva O, Ernst C, Higgins N, Schmatchenko V (2013) The carboxy-termina segment of the human LINE-1 ORF2 protein is involved in RNA binding. FEBS Open Bio 3: 433-437.

10. Miglino N, Lardinois D, Sadowski C, Tamm M, Borger P (2012) Cigarette smoke inhibits lung fibroblast proliferation by translational mechanisms. Eur Respir J 39: 705-711.

11. Yoshida T, Tuder RM (2007) Pathobiology of cigarette smoke-induced chronic obstructive pulmonary disease. Physiol Rev 87: 1047-1082.

12. Faulkner GJ, Kimura Y, Daub CO, Wani S, Plessy C, et al. (2009) The regulated retrotransposon transcriptome of mammalian cells. Nat Genet 41: 563-571.

13. Singer T, McConnell MJ, Marchetto MC, Coufal NG, Gage FH (2011) LINE-1 retrotransposons: Mediators of somatic variation in neuronal genomes. Trends Neurosci 33: 345-354.

14. Shukla R, Upton KR, Munoz-Lopez M, Gerhardt DJ, Fisher ME, et al. (2013) Endogenous retrotransposition activates oncogenic pathways in hepatocellular carcinoma. Cell 153: 101-111. 